\title{
Epidemiology and Control of Agriculture Related Injury
}

\author{
Sang Baek Koh ${ }^{1}$, Kyung Suk Lee ${ }^{2}$ \\ ${ }^{1}$ Department of Preventive Medicine, Wonju College of Medicne, Yonsei University, Wonju 220-710 \\ ${ }^{2}$ Rural Development Administration, Suwon 441-707
}

\begin{abstract}
Objective: The purpose were understanding the epidemiological characteristics of work related injuries of the farmer and establishing injury prevention and control activity. Background: Agriculture is one of the most hazardous industry and job in Korea. Method: We reviewed previous reports regarding the agricultural injury, injury prevention and control. Results: In the agricultural total injury, there were 45,342 hospitalized injury to farmers, injury rate was 35.8/1,000 farmers/years. Of these injuries, 52.6 percent were classed as work related injury. The farm-related injury rate was 17.5/1,000 farmers/years by analysis of Safety Aid System of Farm Workers. There were 2.4 times as incidence rate for farmers compared to non-farmers. Conclusion: Several strategies are available for injury prevention and control. They are as follows; social concern, survey of farm related injury, injury prevention, injury surveillance system and injury compensation.
\end{abstract}

Keywords: Agriculture, Injury, Injury surveillance

\section{Introduction}

우리나라에서 주목 받고 있는 주요 건강문제인 만성질환 의 고 위험군이 소아나 노인인 것과는 달리 손상의 고 위험 군은 주로 경제활동인구의 저소득층인 것으로 알려져 있다. 즉, 일을 하는 과정에서 발생함으로써 실질적인 사회적 비 용은 다른 질환에 비해 상대적으로 더 클 것으로 추정된다.

실제 외국의 경우 20 세에서 64 세 사이의 인구 중에서 발 생하는 모든 손상의 $1 / 3$ 은 직업에 의해 발생하며 $\mathrm{NCHS}$, 1985), 손상으로 인한 사망의 $1 / 6$ 은 직업 손상으로 조사되 었다(Baker 등, 1992).

미국의 경우 직업 손상은 사망과 장애의 주요한 원인이 었다. 작업관련 손상은 장애의 두 번째 순위를 차지하였다. 뿐만 아니라 직업 손상은 인력손실과 함께 실제적인 재정 손실과 생산력을 감소시킨다. 미국 국가안전보장회의에서는 2001년 미국에서의 직업 손상은 390만으로 추산하였다. 이 로 인해 8,500만 작업 손실일을 기록하였으며, 1,321 억 달 러의 총 비용이 들었다(Rosenstock 등, 2005).
특히 직업 손상 중에서 농업인들의 손상은 규모나 중등도 측면에서 큰 문제로 지적되고 있다. 국제노동기구(ILO)에 서는 광업, 건설업과 함께 농업을 직업안전 측면에서 가장 우선순위를 두어야 할 산업이라고 하였다. 타 산업의 경우 치명적 손상이 감소하는 경향을 보이고 있는 반면, 농업의 경우 지속적으로 높은 상태를 유지하고 있다(ILO, 2009).

각 국가별로 살펴보면 미국의 경우 농업인을 대상으로 연 간 사망률은 타 산업에 비해 4 5배에 이르고 있다(표 1). 치명적 손상의 경우도, 전 산업의 손상의 비해 농업 손상이 매우 높다. 미국 뿐만 아니라 유럽 15 개 국의 손상통계 역시 농업 손상이 매우 높음을 확인할 수 있다(그림 1). 호주의 경우도 농업의 치명적 손상의 경우 전 경제활동인구의 평균 손상의 3 4배 정도 높았다.

우리나라에서도 근로복지공단 산재 손상 통계를 보더라도 농업이 광업 및 건설업 보다 높아, 전체 농업인을 포함할 경 우 상당히 높을 것으로 추정하고 있다.

그럼에도 불구하고 우리나라에서는 농업 손상의 발생 현 황을 파악하고 이를 관리하기 위한 제도적 지원이나 정책은 드물었다. 또한 농업 손상에 대한 예방대책을 강구함에 있어

Corresponding Author: Sang Baek Koh. Department of Preventive Medicine, Wonju College of Medicne, Yonsei University, Wonju 220-710.

Mobile: 010-4226-0422, E-mail: kohhj@yonsei.ac.kr

Copyright@2011 by Ergonomics Society of Korea(pISSN:1229-1684 eISSN:2093-8462). All right reserved. 


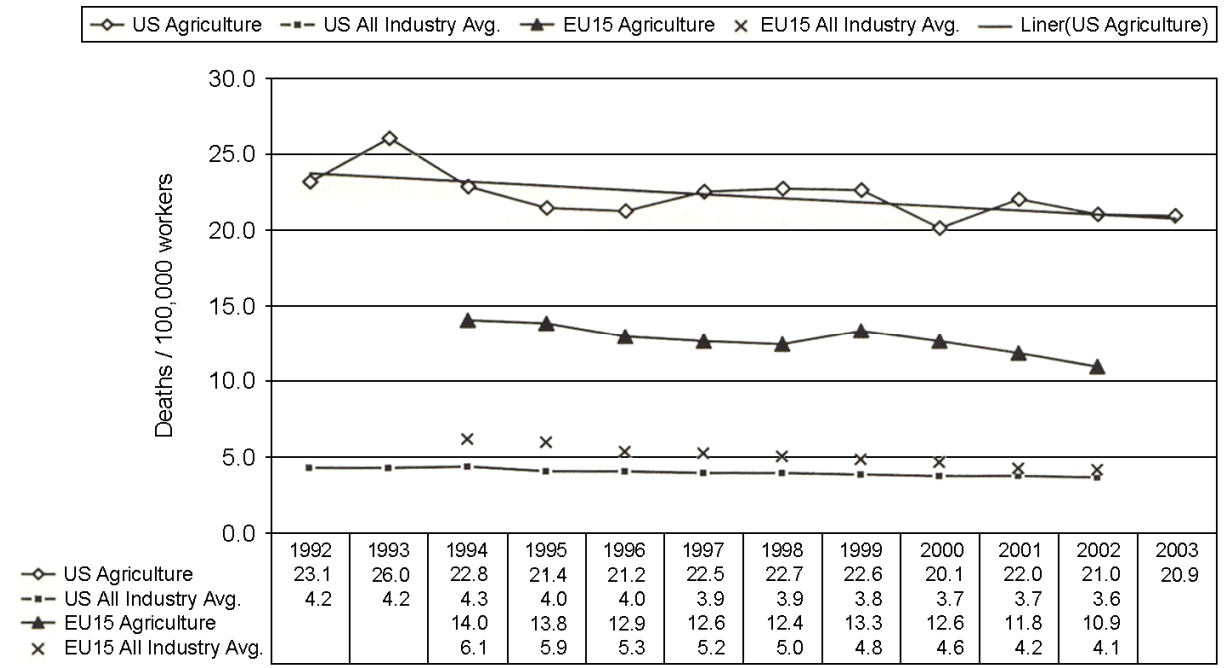

Figure 1. Incidence of fatal injuries by America and Europe

Table 1. Number of rate of fatal occupational injuries in the United State in 2002

\begin{tabular}{l|c|c|c}
\hline & $\mathrm{N}$ & $\%$ & Rate $^{*}$ \\
\hline Industrial division & & & \\
\hline Construction & 1121 & 20.3 & 12.2 \\
\hline Transportation & 910 & 16.5 & 11.3 \\
\hline Agriculture & $\mathbf{7 8 9}$ & $\mathbf{1 4 . 3}$ & $\mathbf{2 2 . 7}$ \\
\hline Services & 680 & 12.3 & 1.7 \\
\hline Manufacturing & 563 & 10.2 & 3.1 \\
\hline Government & 554 & 10.0 & 2.7 \\
\hline Retail trade & 487 & 8.8 & 2.1 \\
\hline Wholesale trade & 205 & 3.7 & 4 \\
\hline Mining & 121 & 2.2 & 23.5 \\
\hline Finance & 87 & 1.6 & 1 \\
\hline Selected occupation & & & \\
\hline Truck drivers & 808 & 14.6 & 25.0 \\
\hline Farm occupations & $\mathbf{5 1 9}$ & $\mathbf{9 . 4}$ & $\mathbf{2 8 . 0}$ \\
\hline Sales occupations & 347 & 6.3 & 2.1 \\
\hline Construction labors & 302 & 5.5 & 27.7 \\
\hline Other labors & 181 & 3.3 & 14.2 \\
\hline Groundkeepers & 146 & 2.6 & 15.0 \\
\hline Police & 140 & 2.5 & 11.6 \\
\hline Electrician & 116 & 2.1 & 13.5 \\
\hline Carpenters & 108 & 2.0 & 6.9 \\
\hline Total & $\mathbf{5 5 2 4}$ & $\mathbf{1 0 0}$ & $\mathbf{4 . 0}$ \\
\hline Falites pen & & \\
\hline
\end{tabular}

*Fatalities per 100,000 persons employed

Source: Rosenstock, 2005
중요한 것은 일반질환과는 달리 상당히 많은 손상들이 일반 개인 손상 또는 교통사고로 분류하여 저평가되고 있다는 점 이다.

따라서 이 글의 목적은 농업인 손상 현황을 알아보고, 농 업인 손상을 예방하고 관리할 수 있는 방안을 알아보고자 하였다.

\section{Epidemiological Characteristics of Agricultural Injury}

\subsection{Total agricultural injury included non-work related injury}

우리나라 농업인의 직업적 원인이든 비직업적 원인이든 농업인에게 발생하는 모든 손상의 규모를 먼저 파악하였다 (Koh, 2007). 농업인은 농림부에서 건강보험료를 지원하기 위하여 파악된 농업세대주 자료를 이용하였고, 그 후 세대 원을 파악한 후 농업인 손상 파악을 위한 대상집단으로 정의하였다. 그 결과 농업세대주는 남자 $1,048,863$ 명, 여자 256,386 명으로 총 $1,305,249$ 명이었다. 농업세대원을 포함 한 농업인 인구는 남자 2,590,688명, 여자 2,436,791명으 로 총 $5,027,479$ 명이었다.

분석자료는 $\mathrm{Kim}$ 등 (2002)이 통계청 사망 자료, 건강보 험청구자료, 자동차보험처리종결자료, 산업재해요양승인자료 등을 결합하여 구축한 전국손상자료에 농업인을 파악할 수 있는 자료를 결합하여 농업인의 전국 손상 규모를 파악하였 다(Koh, 2007). 


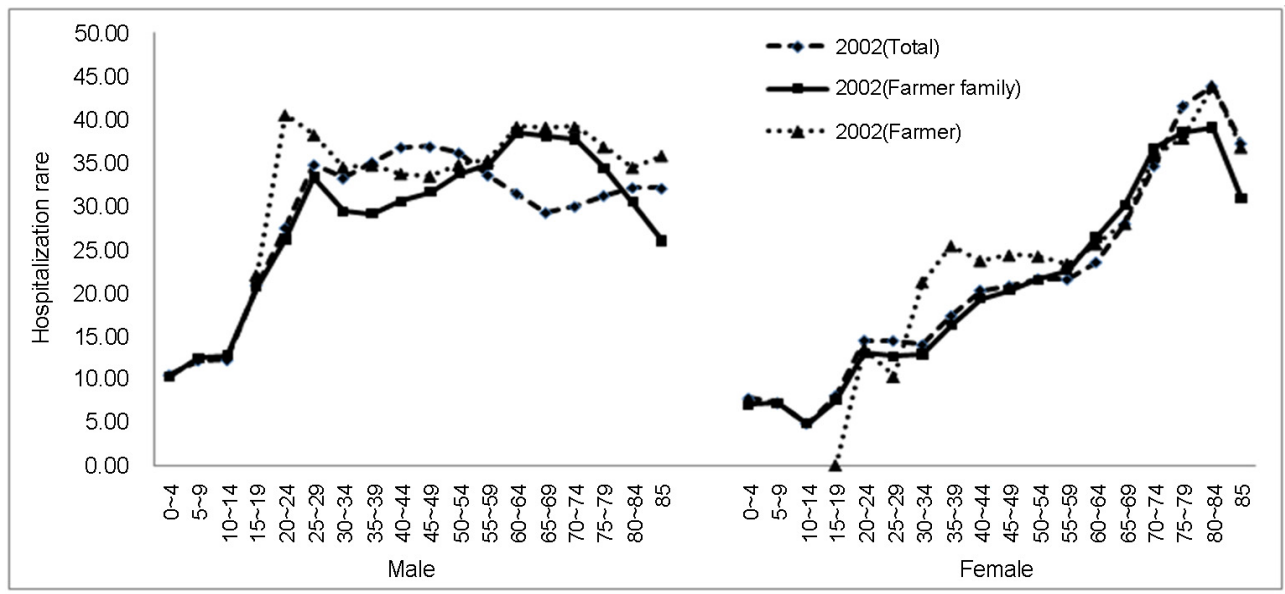

Figure 2. Rate of injury requiring hospitalized by age and sex Source: Koh SB, 2007

먼저 발생건수의 경우, 전국민 손상의 경우 남자가 여자보 다 높았다. 연령별로는 20 54세 경제활동인구에서 손상 발 생건수가 높고, 고 연령층 손상 발생건수는 낮았다. 반면 농 업인(세대원 포함)은 사망의 경우 남자가 여자보다 발생건 수가 높았으며, 일반인구집단과는 달리 남자의 경우 55 75 세에 손상사망이 집중되어 있다. 입원 손상의 경우 연령별로 는 경제활동인구인 20 54세 사이에 손상 발생건수가 여전 히 높지만, 60 75세 사이의 고 연령층에서의 손상 발생건 수가 더 높았다. 여자의 경우 젊은 연령층보다 고 연령층에 서 손상 발생건수가 높았다. 농업세대주의 경우 남자가 여 자보다 발생건수가 많다. 연령별로는 전국민과 농업세대원의 젊은층에서 보였던 높은 발생빈도는 보이지 않고, 고 연령 층 손상빈도를 보이고 있다. 여자의 경우도 55 75세 사이 에서 높은 손상 발생빈도를 보이고 있다. 외래 손상의 경우 도 농업인 및 농업세대주 모두 전국민 손상에 비해 고 연령 층 손상 발생건수가 높다.

사망, 입원 및 외래 손상 발생률도 사망의 경우 남자가 여 자보다 발생률이 높았으며, 연령별로는 연령이 증가할수록 발생률이 증가하였다. 농업인의 경우도 매년 손상 패턴은 유사하였으며, 연령이 증가할수록 사망 손상 발생률이 증가 하였다.

전국민 입원 손상 발생률(천인률)은 2001년, 2002년, 2003 년이 각각 $22.57,22.31,25.06$ 이었고, 농업인(세대원 포함) 은 각각 $24.07,23.07,25.67$ 이었으며, 농업세대주는 각각 $35.86,34.86,37.49$ 이었다. 그 결과 농업세대주가 입 원 손상 발생률이 가장 높았으며, 농업인, 전국민 순이었다.

전국민 입원 손상 발생률은 남자의 경우 20 54세 사이의 경제활동 연령대의 손상 발생률이 높았다, 반면 여자의 경우 연령이 증가할수록 입원 손상 발생률이 증가하였다. 농업인
(세대원 포함)의 경우 연령별로는 경제활동인구인 20 54세 사이에 손상 발생률이 여전히 높지만, 60 75세 사이의 고 연령층에서의 손상 발생률이 훨씬 높게 유지되고 있었다. 여자의 경우 젊은 연령층보다 고 연령층에서 손상 발생률이 높다. 농업세대주의 경우 남자가 여자보다 발생률이 높다. 그러나 고 연령층에서는 여자가 남자보다 발생률이 높다. 연 령별로는 연령이 증가할수록 발생률이 증가하였다(그림 2).

전국민 외래 손상 발생률(천인률)은 2001년, 2002년, 2003년이 각각 $184.8,193.5,207.5$ 이었고, 농업인(세대원 포함) 은 각각 $212.5,220.7,236.5$ 이었으며, 농업세대주는 각각 $259.5,263.5,279.9$ 이었다. 그 결과 농업세대주가 외 래 손상 발생률이 가장 높았으며, 농업인, 전국민 순이었다. 연령별 발생률 현황은 농업인(세대원 포함)의 경우 연령이 증가할수록 발생률이 높다가 70세 이후 고 연령층에서 감소 하였으며, 농업세대주의 경우 전반적으로 손상 발생률이 고 연령층 쪽으로 치우쳐 있다(그림 3).

전국민, 농업인(세대원 포함) 및 농업인 세대주의 총 손상, 사망, 입원 및 외래 손상 발생건수 및 발생률을 요약하면 표 2 와 같다. 입원 이상의 손상 발생률은 농업인 세대주의 경우 천명당 35.86명으로 조사되었으며, 손상 중등도에 따 른 중증 손상 발생률은 전국민 2.2, 농업인(세대원 포함) 3.43 , 농업인 세대주 6.05 로 농업인 세대주가 전국민보다 3 배 정도 손상 발생률이 높았다.

\subsection{Percentage of work related injury among total injury}

농업인의 총 손상은 그 원인이 직업적 원인인지 비직업적 원인인지 확실하지 않다. 따라서 총 손상 중 직업적 원인이 


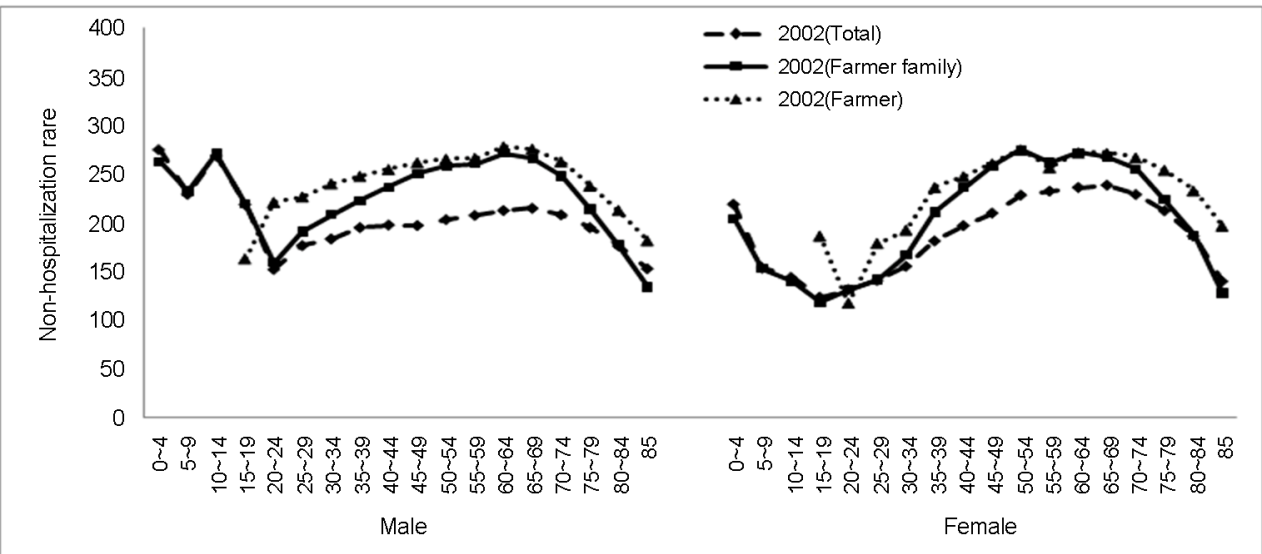

Figure 3. Rate of injury requiring non-hospitalized by age and sex Source: Koh SB, 2007

Table 2. Incidence counts and Rate(per 1,000) of injuries by total injury, death, hospitalized, non-hospitalized 2001 2003

\begin{tabular}{c|c|c|c|c}
\hline $\begin{array}{c}\text { Injury } \\
\text { severity }\end{array}$ & $\begin{array}{c}\text { Total } \\
\text { injury }\end{array}$ & Death & Hospitalized & $\begin{array}{c}\text { Non- } \\
\text { hospitalized }\end{array}$ \\
\hline $\begin{array}{c}\text { National } \\
\text { population }\end{array}$ & 207.22 & 0.64 & 22.57 & 184.80 \\
\hline $\begin{array}{c}\text { Farmer } \\
\text { family }\end{array}$ & 237.53 & 0.86 & 24.07 & 212.59 \\
\hline Farmer & 295.84 & - & 35.86 & 259.53 \\
\hline $\begin{array}{c}\text { Injury } \\
\text { severity }\end{array}$ & $\begin{array}{c}\text { Total } \\
\text { injury }\end{array}$ & Mild & Moderate & Severe \\
\hline $\begin{array}{c}\text { National } \\
\text { population }\end{array}$ & 207.22 & 181.58 & 22.78 & 2.22 \\
\hline $\begin{array}{c}\text { Farmer } \\
\text { family }\end{array}$ & 237.53 & 206.32 & 26.91 & 3.43 \\
\hline Farmer & 295.84 & 254.83 & 34.51 & 6.05 \\
\hline
\end{tabular}

얼마만큼 되는지를 파악하는 것은 중요한 문제다. 따라서 Yim 등(2007)은 2006년 건강보험자료에서 주상병 및 부 상병으로 $\mathrm{S}$ 또는 $\mathrm{T}$ 코드인 손상으로 진료받았던 사람들 중 중등도, 성별, 연령 변수를 이용하여 층화 추줄한 다양한 직 업군으로 구성된 18,000 명의 전화 설문조사 결과를 참고하 였다.

전체 조사대상자의 손상 원인 중 직업 및 경제활동으로 인한 손상의 비율이 4,045 명 $22.5 \%$ 로 사고 발생 원인 중 가장 높은 비율을 차지하였다. 직업적 손상 이외에도 이동 $16.3 \%$, 일상생활 $15.9 \%$, 여가 및 취미생활 $15.7 \%$ 순으로 높은 것으로 조사되었다. 이 자료를 실질적으로 직업을 가지 고 경제활동을 하는 19 세 이상을 대상으로 각 직업별로 직 업 손상 비율을 조사하였을 때 전체 직업 $25.9 \%$ 보다 훨씬 높은 $52.6 \%$ 로 조사되었다. 이는 총 손상 중 절반 이상이 직
업 및 경제활동과 관련되어 있다는 의미로 해석된다(표 3). 이를 다시 산업별 분류에 따라 직업 손상 비율이 낮은 금 융보험업과 비교하여 보면, 건설업이 가장 위험한 산업이었 고, 두 번째로 농림어업이 위험하였다. 이는 금융보험업 보 다 직업 손상 위험도가 23.9배 높았고, 제조업 14.2보다 훨 씬 높은 수치였다(표 4).

Table 3. Distribution of work-related injury among total injury by job category and sex

\begin{tabular}{|c|c|c|c|}
\hline \multirow{2}{*}{ Job category } & \multicolumn{2}{|c|}{ Sex } & \multirow{2}{*}{ Total } \\
\hline & Male & Female & \\
\hline Agricultural worker & 55.2 & 46.0 & 52.6 \\
\hline $\begin{array}{l}\text { Sales and Customer } \\
\text { service managers }\end{array}$ & 43.0 & 40.3 & 42.0 \\
\hline Sales worker & 48.9 & 44.0 & 46.5 \\
\hline Elementary worker & 60.3 & 50.0 & 57.9 \\
\hline Clerks and service worker & 31.2 & 25.5 & 28.9 \\
\hline Housewife & 7.1 & 1.1 & 1.1 \\
\hline Student & 2.7 & 1.8 & 2.4 \\
\hline Armed force & 27.6 & - & 27.6 \\
\hline Public official & 47.0 & 31.6 & 43.5 \\
\hline Others & 2.6 & 2.3 & 2.5 \\
\hline Total & 36.2 & 15.2 & 25.9 \\
\hline
\end{tabular}

Source: Yim J, 2007

\subsection{Patterns and characteristics of agriculture related} injury by analysis of Safty Aid System of Farm Workers

농업인 안전공제는 산재보험 가입대상에서 제외되는 농업 
Table 4. The Odds ratio of occupational injury by industrial classification

\begin{tabular}{|c|c|c|c|c|}
\hline $\begin{array}{c}\text { Industrial } \\
\text { classification }\end{array}$ & Control & $\begin{array}{l}\text { Injury } \\
\text { case }\end{array}$ & $\begin{array}{l}\text { Odds } \\
\text { ratio }\end{array}$ & 95\% C.I. \\
\hline $\begin{array}{l}\text { Financial and } \\
\text { insurance }\end{array}$ & 82 & 8 & 1.00 & - \\
\hline Construction & 145 & 399 & 28.21 & $13.32 \sim 59.74$ \\
\hline $\begin{array}{l}\text { Agriculture, forestry } \\
\text { and fishing }\end{array}$ & 117 & 223 & 23.92 & $11.21 \sim 51.02$ \\
\hline $\begin{array}{l}\text { Manufacturing } \\
\text { industry }\end{array}$ & 353 & 492 & 14.29 & $6.83 \sim 29.91$ \\
\hline Transportation & 84 & 99 & 12.08 & $5.53 \sim 26.41$ \\
\hline $\begin{array}{l}\text { Wholesale and } \\
\text { retail trade }\end{array}$ & 143 & 137 & 9.82 & $4.58 \sim 21.06$ \\
\hline $\begin{array}{l}\text { Other service } \\
\text { activities }\end{array}$ & 756 & 416 & 5.64 & $2.70 \sim 11.77$ \\
\hline Other industries & 258 & 133 & 5.28 & $2.48 \sim 11.25$ \\
\hline Mining & 8 & 4 & 5.13 & $1.26 \sim 20.84$ \\
\hline $\begin{array}{l}\text { Electricity, gas and } \\
\text { water supply }\end{array}$ & 54 & 21 & 3.99 & $1.65 \sim 9.65$ \\
\hline
\end{tabular}

Souce: Yim J, 2007

인을 각종 재해로부터 보호하기 위해 정부가 공제료 50\%, 농가가 $50 \%$ 를 부담하는 국가보조사업이다. 안전공제는 만 15세에서 84세의 농업인을 가입대상으로 한다. 2004년 12 월 기준으로 690,343 명이 가입되어 있다. 대략 전체 농 림업의 경제활동인구 $40 \%$ 가량에 해당한다. 농업인 안전공 제는 대상자의 포괄 범위와 보상의 내용에 있어 산재보험에 비해 그 수준이 낮다는 한계를 가지고 있음에도 불구하고, 현재 수준에서 농업인의 재해 양상과 특성에 대한 전반적인 상황을 살펴 볼 수 있는 거의 유일한 자료로 할 수 있다. 따 라서 안전공제에 가입한 대상자 중에서 손상 경험자를 산출 하면 이 손상은 직업적 원인에 가장 가까운 통계수치로 가 정할 수 있을 것이다. Lee 등(2007)이 분석한 결과에 의하 면 2004년부터 2006년까지 농업인의 재해 천인율을 17.5 로 조사되었다. 연령별로는 60 64세 인구집단에서 26.86 으로 가장 높은 발생률을 보였고, 55 59세 20.57, 65 69 세 18.72 순으로 높았다(표 5).

\subsection{Current status of agricultural injury in Korea}

우리나라 농업인의 직업관련 손상 발생률은 Lee 등 (2007)이 보고한 안전공제 천인율 17.5는 Koh 등(2007) 이 보고한 농업인 총 손상의 인원 손상의 천인율 36.86 에 절반에 가까운 수치로 Yim 등(2007)이 조사한 농림어업인 중 직업 손상 분율이 총 손상의 $52.6 \%$ 에 해당하는 결과라 할 수 있다. 이는 2005년 산재 천인률 7.7 과 비교하여 볼
Table 5. Incidence of farm-related injury by age and years Unit: incidence rate(/1,000 farmers/years )

\begin{tabular}{c|c|c|c|c}
\hline \multirow{2}{*}{ Age } & \multicolumn{3}{|c|}{ Years } & \multirow{2}{*}{ Total } \\
\cline { 2 - 4 } & 2004 & 2005 & 2006 & \\
\hline $20 \sim 24$ & 75.19 & 63.38 & 66.67 & 68.15 \\
\hline $25 \sim 29$ & 24.98 & 21.44 & 24.65 & 23.59 \\
\hline $30 \sim 34$ & 25.21 & 19.58 & 15.21 & 20.16 \\
\hline $35 \sim 39$ & 20.40 & 19.32 & 14.33 & 17.99 \\
\hline $40 \sim 44$ & 25.34 & 23.72 & 17.36 & 22.14 \\
\hline $45 \sim 49$ & 17.08 & 19.15 & 16.99 & 17.75 \\
\hline $50 \sim 54$ & 17.23 & 18.35 & 16.31 & 17.31 \\
\hline $55 \sim 59$ & 19.35 & 22.12 & 20.24 & 20.57 \\
\hline $60 \sim 64$ & 26.47 & 29.64 & 24.39 & 26.86 \\
\hline $65 \sim 69$ & 17.22 & 19.68 & 19.30 & 18.72 \\
\hline $70 \sim 74$ & 8.77 & 12.12 & 13.99 & 11.57 \\
\hline $75 \sim 79$ & 3.92 & 6.62 & 7.77 & 6.05 \\
\hline $80 \sim 84$ & 1.48 & 2.68 & 3.19 & 2.42 \\
\hline 85 & 0.00 & 0.46 & 0.00 & 0.17 \\
\hline Average & $\mathbf{1 6 . 5 6}$ & $\mathbf{1 8 . 7 8}$ & $\mathbf{1 7 . 1 3}$ & $\mathbf{1 7 . 5 0}$ \\
\hline Source Lee SJ & 2007 & & &
\end{tabular}

Source: Lee SJ, 2007

때 농업인은 우리나라 전체 산업 산재 평균보다 약 2.4 배에 높은 위험한 직업군으로 결론 내릴 수 있다.

\section{Strategies of Injury Prevention and Control}

우리나라 농업인의 손상 현황을 보면 심각한 수준임을 알 수 있다. 그러나 여전히 체계적인 조사와 접근이 미흡하다. 따라서 농업인의 손상을 관리하기 위해서는 다음과 같은 전 략적 과제가 필요하다.

\subsection{Social concern of agricultural injury}

농업인 손상에 대한 사회적 관심이 집중되어야 한다. 그 동안 우리나라에서는 전통적인 제조업 중심의 손상에 관심 을 집중하여 왔다. 농업인의 대한 손상은 산업재해 대상자가 아니라는 점에서 노동부의 관심대상이 아니었고, 산재보험으 로부터 제외되어 사각지대에 놓여 있었다. 농림부에서는 생 산성 위주에 관심을 가지는 한편 농업인 손상 및 건강에 대 한 관심은 부차적이었다. 표준직업분류표를 기준으로 다른 직업과 비교하여 볼 때 농업인은 300만명 정도로 구 규모면 
에서도 결코 작지 않다. 또한 손상 규모와 중증도 면에서도 매우 높은 손상 발생률을 보여 사회적 부담이 크며, 다양한 유해요인에 노출된다는 점을 고려하여 볼 때 주요한 관심대 상이라고 할 수 있다. 따라서 정부 뿐만 아니라 많은 보건전 문가들의 관심도 필요하다.

\subsection{Survey of farm-related injury}

직업 손상 보고체계를 구축하여야 한다. 농작업 손상과 관련된 연구 및 정책수립의 우선순위 결정은 정확한 농작업 손상 발생을 양적, 질적으로 파악해야 가능하나 우리나라는 실제 농작업 손상 발생 규모를 알 수 있는 통계가 부재하 였다.

지난 40여 년 간 직업 손상을 산재보험법에 의해 요양승 인된 통계를 국가의 직업 손상의 공식통계로 사용하여 왔지 만 농업인은 여기에 포함되지 않고 있고, 단지 농공 단지에 근무하는 일부 농업인의 손상만이 포함되어 있을 뿐이다.

반면 선진 각 국은 농작업 재해 발생을 정확하게 파악하기 위하여 직업 손상 발생경향을 나타낼 수 있는 각종 통계시스 템을 갖고 있으며, 여기에 농작업 손상을 포함하여 다루고 있다.

미국의 경우 주단위로 보상통계를 산출하는 이외에 직업 손상의 실제 발생 규모를 파악하기 위하여 직업 손상으로 인 한 치명적 손상에 대하여 CFOI(Census of Fatal Occupational Injuries, CFOI) 및 NTOF(National Traumatic Occupational Fatalities)이라고 불리는 통계를 산출하고 있으며, 비치명적 손상 및 질병에 대해서는 매년 직업성 손 상 및 질병 서베이(Survey of Occupational Injuries and Illness, SOII)를 실시하여 통계를 산출하고 농작업 재해의 중요성을 부각하고 있다. 따라서 우리나라도 독자적인 농작 업 재해통계 규모를 산출할 수 있는 보고체계를 갖추는 것 이 필요하다.

\subsection{Injury prevention}

농업인 손상관련 예방대책을 마련하여야 한다. 그 동안 농 작업 손상을 예방이 가능한 보건학적 문제로 인식하기보다 우연한 요인 또는 부주의로 인해 발생하는 사고(accident) 로 이해하였다. 이러한 인식의 특징은 손상을 유발하는 위험 요인을 규명하고 이에 대한 적절한 예방대책을 수립하기 위 한 전략을 어렵게 한다. 그 결과 손상예방에 무관심한 여러 가지 한계를 노정하였다.

이를 극복하기 위해서는 손상 발생단계에서 최종 종결 에 이르는 과정을 손상스펙트럼으로 이해하고 각각의 단 계에 맞는 예방방법을 모색하여야 한다. 즉 손상을 노출 (exposure)-사고의 발생 (event) -손상의 진행 (injury) 장애(disability) -사망(death)의 과정으로 이해하고 각각 의 과정에 요인에의 노출-사고의 발생단계는 1 차 예방으로, 사고의 발생-손상의 진행단계는 2 차 예방으로, 손상의 진행 -장애의 발생에는 3 차 예방으로 대체하여야 한다.

\subsection{Injury surveillance system and cohort study}

장기적인 코호트 연구체계 및 감시체계를 구축하여야 한 다. 직업 손상 연구에서 체계적인 예방과 관리를 위해서는 장기적 연구체계 구축과 감시체계 수립이 필요하다. 외국에 연구에서와 같이 향후 연구의 초점은 직업 손상의 원인, 경 과과정 및 결과에 영향을 주는 예측이자를 찾는 코호트 연 구가 필요하다. 또한 능동적 손상 감시체계와 수동적 손상 감시체계를 함께 운영함으로써 코호트 연구체계와 병용 보 완할 수 있다.

\subsection{Injury compensation}

재해보상체계를 마련하여야 한다. 현재 제조업 및 기타 산 업에 종사하는 근로자의 경우 재해 발생 시 이를 대처하기 위한 제도로서 산재보상보험을 운영하고 있으며, 이는 사회 안전망으로서 최소한의 장치로 그 역할을 하고 있다. 그러나 농업인의 경우 타 산업에 비해 손상 규모 및 중증도가 높음 에도 불구하고 직접적인 고용관계에 있지 않아 산재보상보 험에 제외되어 있으며, 손상이 발생할 경우 제도적으로 사회 안전망이 구축되어 있지 않은 상태이다. 따라서 손상으로 인 하여 문제가 발생할 경우 이를 조기에 치료하고 보상할 수 있는 보상체계가 시급하다.

\section{Acknowledgements}

This work was supported by grants from "Research program for Agriculture Science \& Technology Development(PJ006422062011)" Rural Development Administration.

\section{References}

Baker, S. P., Smakoff, S., Fisher, R. S. and Van Buren, C. B., Fatal occupational injuries, JAMA, 248, 692-697, 1982.

Bonnie, R. J., Fulco, C. E. and Liverman, C. T., Reducing the burden of 
injury-Advancing prevention and treatment. IOM. National Academy Press, Washington D.C. 1999.

Koh, S. B., Evaluation and analysis of agricultural injuries, Ministry for Food, Agriculture, Forestry and Fisheries, 2007.

Kim, J. Y., Assessment of the epidemiologic characteristics of injuries to estimate the burden of disease in Korea, Ministry of Health and Welfare. 2002.

Lee, S. J., A study on patterns and characteristics of agriculture related injury by analysis of Safty Aid System of Farm Workers. Ministry for Food, Agriculture, Forestry and Fisheries, 2007.

National Safty Council. Injury facts. Itasca, IL: National Safty Council, 2002.

Rosenstock, L., Cullen, M. R., Brodkin, C. A. and Redlich, C. A., Textbook of clinical occupational and environmental medcine, Elsevir, Philadelpia, 825-833, 2005.

Public Health Division Department of Human Services. Victorian Burden of Disease Study, Morbidity, 1999

Yim, J., The study on occupatinal safety for strategy of National safety management, Korea Occupational Safety and Health Agency, 2007.

\section{Author listings}

Sang Baek Koh: kohhj@yonsei.ac.kr

Highest degree: $\mathrm{PhD}$, Department of Medicine, Konkuk University Position title: Professor, Department of Preventive Medicine, Yonsei University

Areas of interest: Occupational and Environment Medince

\section{Kyung Suk Lee}

Highest degree: $\mathrm{PhD}$, Department of Clothing \& textile, Seoul National University

Position title: Researcher, Rural Development Administration Areas of interest: Agricultural safety and health

Date Received : 2011-06-20

Date Revised :2011-07-26

Date Accepted : 2011-07-27 